\title{
Landscape Capacity for Supplying Ecosystem Services in Taiwan Alishan National Scenic Area
}

\author{
Fu-Chiang Yang and Yi-Tui Chen
}

\begin{abstract}
For some service facilities, the unused service capacity cannot be stocked overnight and will become a burden to the service provider. The main purpose of this article is to analyze the effects of seasonality on capacity choice decisions and examine the firm's pricing strategies. We present a mathematical model and find that higher operating costs lead to lower service fees in booming seasons and higher service fee in normal seasons, but the capacity should be decreased; the higher proportion of booming seasons in a year results in higher service fee in booming seasons and lower service fee in normal seasons, and the capacity should be increased. The price markup in booming seasons is higher if the proportion of booming seasons increase, but lower if operating costs increase.
\end{abstract}

Index Terms-Expected costs, optimization, service capacity, seasonal demand.

\section{INTRODUCTION}

In many countries the service sector has become an increasingly important contributor for economic growth and social benefit. The growing demand for service is leading to accelerate the development on the undeveloped area. In Taiwan the number of employee in service sector has reached to 559 thousand, accounting for $55.6 \%$ of total employee in 2014 [1]. The outputs produced by service sector in Taiwan accounts for $30.6 \%$ of GDP in 1991 and reached to $68.4 \%$ in 2014 [2]. Under such a circumstance, many firms in service industry are facing a challenge from the rapid change of various market demands for services. In service industry, the capacity for a service facility is very important and essential for the firm to satisfy customer's needs and to gain business competitiveness. Xu and Zhuan [3] indicate that the tradeoff between the benefits and costs may decide the optimum capacity. Therefore, the capacity management has become one of the most difficult and essential management tasks [4]. Pullman and Rodgers [5], Bozarth and Handfield [6] indicate that the development of capacity strategy is a key operational function for all leisure-related enterprises. Malik and Bhat [7] adopt a management strategy to determine the service capacity for achieving sustainable tourism. More capacity of facilities will result in more operating costs but insufficient capacity leads to increase in customer dissatisfaction or immediate loss of sales revenues. Examples of such problems (capacity management) include studies of hotel beds or restaurant tables, infrastructure in a park, transportation

Manuscript received October 30, 2017; revised November 30, 2017.

F. C. Yang is with De Lin Institute of Technology, Taiwan (e-mail: yitui@ntunhs.edu.tw).

Y. T. Chen is with National Taipei University of Nursing and Health Sciences, Taiwan (e-mail: fuchiang@mail.hdut.edu.tw). system, university library network system, etc.

Corsten and Stuhlmann [8] argue that service is interpreted as 'offers to spend time' and service quality depends on the duration of service production. An appropriate capacity choice is required to satisfy customers with fewer costs. In general, these problems can be classified into queue problem and non-queue problem. The former problems such as hospitality service, transportation, etc. allow queuing when service facilities are insufficient and regard queuing time as an indicator of service quality. The effects of queuing delay result in congestion and increase time costs on customers. A great number of literature have focused on the development of capacity management decisions [9]-[12]. For example, Harper et al. [13] consider the location of the service centers, service capacities, geographical distribution of patients, and ease of access to the health services in modeling the health service. Glazer and Rothenberg [14] discuss the provision of medical care with the existence of the demand for medical insurance and the moral hazard problems. They argue that an increase in capacity is seen as an increase in capital so that an incentive system to results in a decrease in the time required to serve a customer since rationing is costly and denial of service is difficult and conclude that a reduction in capacity may increase social welfare. Daniel [15] presents the most sophisticated analysis of congestion pricing to resolve airport traffic problems by maximizing capacity utilization, overall revenue or net returns. Calfee and Winston [16] present a model to solve highway congestion problem by imposing a fee on each motorist so that the marginal private costs born by the motorist is equal to the marginal social costs. These studies have shown that simple fixed peak-period pricing policies rather than continuously varying prices policies can improve traffic flows and increase economic welfare.

In contrast, the latter problem does not allow queuing. Such a problem can be applied to the capacity determination of a hotel, a recreation infrastructure, or a theater that is characterized with high fixed costs and no space for inventory in an ever-changing market. The management must determine an optimal capacity to balance the high loss of empty facilities (without customer arrivals) in normal seasons and the loss of sales revenues due to insufficient capacity in booming seasons. Thompson [17] examines which is better to use dedicated or configurable tables by a simulation model. Miguel and Miguel [18] adopt Harmony Search (HS) and Firefly Algorithm (FA) to solve truss shape and sizing optimization with multiple natural frequency constraints. Desart et al. [19] propose the concept of dynamic and stability of capacity and an airport's plan to mitigate the risk of capacity degradation are taken as integral part. Kimes et al. [20] present a model of the time-based revenue performance measure to maximize the revenue that a 
restaurant can achieve and develop implementation strategies for restaurant revenue management. When customers dislike waiting and have a choice among facilities, they will decide to select service based on "self-optimizing" based on self-interest. For such a problem, Grossman and Brandeau [21] present a model to determine optimal facility prices to induce customers to select facilities by minimizing total costs and show the equal charging customers for the impact that they cause for others.

This paper considers the case that a firm intends to invest on the construction of facilities under uncertainly seasonal market demand and the queuing considered as a condition is not allowed. It needs to determine capacity for a service facility and/or price (service fee) simultaneously to gain benefits. As the company does not want to lose its customers due to insufficient provision, the decision of an appropriate capacity for a service facility is critical to the company's survival and competitiveness. In this paper, our interests focus on the determination of optimal capacity for a service facility by assuming that the firm is a monopoly in providing service and thus it must decide an optimal price and service capacity simultaneously by maximizing the net profit. Through sensitivity analysis the impact of some environmental parameters on capacity and pricing are examined. Due to higher market demand in booming seasons, the service fee will be marked up in booming seasons. We also intend to examine the impacts of operating costs and the proportion of booming seasons on the price markup in booming seasons.

\section{AsSUmPtions AND NOTATIONS}

There are two types of seasons with different customer arrival rates: booming seasons and normal seasons. The customer arrival per day $\mathrm{x}$ in booming seasons is distributed over a truncated normal distribution, i.e. $\mathrm{x} \sim \mathrm{N}+\left(\mu_{1}, \sigma_{1}^{2}\right)$, where $\mu_{1}$ and $\sigma_{1}^{2}$ are the mode and variance of the normal distribution which is truncated below at zero. Similarly, arrival per day y in normal seasons is distributed over a truncated normal distribution, i.e. $\mathrm{y} \sim \mathrm{N}+\left(\mu_{2}, \sigma_{2}^{2}\right)$. This paper assumes that $\mu_{1}$ and $\mu_{2}$ are fixed, given and $\mu_{1}>\mu_{2}$. The following notations of variables are employed in this article.

$x$ : the arrival rate of visitors each day in booming seasons, is a random variable distributed over a truncated normal distribution, i.e.

$$
\mathrm{f}\left(\mathrm{x} \mid \mu_{1}, \sigma_{1}^{2}\right)=\frac{1}{\sqrt{2 \pi} \sigma \phi\left(\mu_{1} / \sigma_{1}\right)} \exp \left\{-\frac{\left(x-\mu_{1}\right)^{2}}{2 \sigma_{1}^{2}}\right\}
$$

where $\mu_{1}$ and of $\sigma_{1}^{2}$ are mode and variance of normal distribution, and $\phi$ is the standard normal cumulative distribution function.

$y$ : the arrival rate of visitors in normal seasons, is a random variable distributed over a truncated normal distribution, i.e.

$$
\mathrm{f}\left(\mathrm{y} \mid \mu_{2}, \sigma_{2}^{2}\right)=\frac{1}{\sqrt{2 \pi} \sigma \phi\left(\mu_{2} / \sigma_{2}\right)} \exp \left\{-\frac{\left(y-\mu_{2}\right)^{2}}{2 \sigma_{2}^{2}}\right\}
$$

$q$ : the proportion of booming seasons in a year, $0<\mathrm{q}<1$.

$k$ : the capacity of the planned facility

$c$ : the unit operating cost

$P$ : service fee (e.g. room fee in a hotel, ticket price for entrance of a theater or a playing park).

$g($ ): market demand for service in booming seasons

$h($ ): market demand for service in normal seasons

$u($ ): the implicit function describing the relationship between $\mu_{1}$ and $\mu_{2}$.

We assume that the firm is a monopoly due to the highly differentiation of the service provided. The decision maker employs the market rule that service fee is a function of demand quantity (customer arrival rates) to determine optimal service fee (e.g. entry fee, or hotel charge) and capacity simultaneously. The decision maker seeks to maximize expected profits by optimizing the service capacity and service fee simultaneously. We consider that the management may adopt two pricing strategies (the same service fee or the different service fee in the two seasons). The analysis and comparison of the pricing strategy are discussed in Section III. The managerial implications arising from the results are discussed in Section IV and we make a brief conclusion in Section V.

\section{ANALYSES AND RESUlTS}

We assume the firm is a monopoly and will choose appropriate pricing strategies to maximize profits based on the market demand law. In other words, higher price (service fee) will reduce means of arrival rate $\mu_{1}$ and $\mu_{2}$ in the two seasons respectively, i.e. $\mathrm{P} 1=\mathrm{g}\left(\mu_{1}\right)$ and $\mathrm{P} 2=\mathrm{h}\left(\mu_{2}\right)$ with properties of $\mathrm{g}^{\prime}\left(\mu_{1}\right)<0$ and h' $\left(\mu_{2}\right)<0$, where P1 and P2 denote service fee in the two seasons respectively. The management may choose different service fees between different seasons or same service fees.

\section{A. Different Service Fee in Different Seasons}

The net profit for the firm becomes $\pi=q g\left(\mu_{1}\right) x+(1-q) h\left(\mu_{2}\right) y-c k$ The decision maker will determine the optimal service fee (representing by mode of arrival rate $\mu_{1}$ and $\mu_{2}$ ) and the capacity for a service facility $\mathrm{k}$ simultaneously by maximizing the expected profit, thus the problem becomes

$$
\begin{gathered}
\underset{k, \mu_{1}, \mu_{2}}{\operatorname{Max}} E(\pi)=q g\left(\mu_{1}\right)\left[\int_{0}^{k} x f\left(x \mid \mu_{1}, \sigma_{1}^{2}\right) d x+\int_{k}^{\infty} k f\left(x \mid \mu_{1}, \sigma_{1}^{2}\right) d x\right] \\
+(1-q) h\left(\mu_{2}\right)\left[\int_{0}^{k} y f\left(y \mid \mu_{2}, \sigma_{2}^{2}\right) d y+\int_{k}^{\infty} k f\left(y \mid \mu_{2}, \sigma_{2}^{2}\right) d y\right]-c k
\end{gathered}
$$

The optimal solutions $\mu_{1}, \mu_{2}$ and $\mathrm{k}$ can be obtained from the necessary conditions Eq. (A1.1) - (A1.3) of this problem (please see Appendix 1). The bracket of the first item on Right-Hand-Side of Eq. (A1.1) represents opportunity costs 
in booming seasons and the bracket of the second item represents opportunity costs in normal seasons. Equation (A1.1) demonstrates that the sum of opportunity costs for the two seasons must be equal to the operating costs.

$0=\frac{\partial E(\pi)}{\partial k}=q g\left(\mu_{1}\right) \frac{1}{\phi\left(\mu_{1} / \sigma_{1}\right)}\left[1-\phi\left(\frac{k-\mu_{1}}{\sigma_{1}}\right)\right]+(1-\mathrm{q})$

$\mathrm{h}\left(\mu_{2}\right) \frac{1}{\phi\left(\mu_{2} / \sigma_{2}\right)}\left[1-\phi\left(\frac{k-\mu_{2}}{\sigma_{2}}\right)\right]-\mathrm{c}$

$0=\frac{\partial E(\pi)}{\partial \mu_{1}}=\left[g^{\prime}\left(\mu_{1}\right) \frac{1}{\phi\left(\mu_{1} / \sigma_{1}\right)}-g\left(\mu_{1}\right) \frac{f\left(\mu_{1} / \sigma_{1}\right)}{\phi^{2}\left(\mu_{1} / \sigma_{1}\right)}\right]$

$\left\{\frac{\sigma_{1}}{\sqrt{2} \pi}\left(e^{-\frac{\mu_{1}^{2}}{2 \sigma_{1}^{2}}}-e^{-\frac{\left(k-\mu_{1}\right)^{2}}{2 \sigma_{1}^{2}}}\right)+\mu_{1}\left[\phi\left(\frac{k-\mu_{1}}{\sigma_{1}}\right)-\phi\left(\frac{-\mu_{1}}{\sigma_{1}}\right)\right]+\mathrm{k}\right.$

$\left(1-\phi\left(\frac{k-\mu_{1}}{\sigma_{1}}\right)\right\}+\mathrm{g}\left(\mu_{1}\right) \frac{1}{\phi\left(\mu_{1} / \sigma_{1}\right)}\left\{\frac{-\mu_{1} \sigma_{1}}{\sqrt{2} \pi} e^{-\frac{\mu_{1}^{2}}{2 \sigma_{1}^{2}}}+\right.$

$\left[\phi\left(\frac{k-\mu_{1}}{\sigma_{1}}\right)-\phi\left(\frac{-\mu_{1}}{\sigma_{1}}\right)\right]+\mu_{1} \sigma_{1} \mathrm{f}\left(\frac{-\mu_{1}}{\sigma_{1}}\right)+\frac{\mu_{1}^{2}}{\sigma_{1}}\left(\mu_{1}-\mathrm{k}\right)$

$\left(1-\phi\left(\frac{k-\mu_{1}}{\sigma_{1}}\right)\right\}$

$0=\frac{\partial E(\pi)}{\partial \mu_{2}}=\left[\mathrm{h}^{\prime}\left(\mu_{2}\right) \frac{1}{\phi\left(\mu_{2} / \sigma_{2}\right)}-\mathrm{h}\left(\mu_{2}\right) \frac{f\left(\mu_{2} / \sigma_{2}\right)}{\phi^{2}\left(\mu_{2} / \sigma_{2}\right)}\right]$

$\left\{\left[\frac{\sigma_{2}}{\sqrt{2} \pi}\left(e^{-\frac{\mu_{2}^{2}}{2 \sigma_{2}^{2}}}-e^{-\frac{\left(k-\mu_{2}\right)^{2}}{2 \sigma^{2}}}\right)+\mu_{2}\left[\left(\phi\left(\frac{k-\mu_{2}}{\sigma_{2}}\right)-\phi\left(\frac{-\mu_{2}}{\sigma_{2}}\right)\right]\right.\right.\right.$

$$
+k\left(1-\phi\left(\frac{k-\mu_{2}}{\sigma_{2}}\right)\right\}+h\left(\mu_{2}\right) \frac{1}{\phi\left(\mu_{2} / \sigma_{2}\right)}
$$

$\left\{\frac{-\mu_{2} \sigma_{2}}{\sqrt{2} \pi} e^{-\frac{\mu_{1}^{2}}{2 \sigma_{1}^{2}}}+\left[\left(\phi\left(\frac{k-\mu_{2}}{\sigma_{2}}\right)-\phi\left(\frac{-\mu_{2}}{\sigma_{2}}\right)\right]+\mu_{2} \sigma_{2} \mathrm{f}\left(\frac{-\mu_{2}}{\sigma_{2}}\right)\right.\right.$

$$
+\frac{\mu_{2}^{2}}{\sigma_{2}}\left(\mu_{2}-\mathrm{k}\right)\left(1-\phi\left(\frac{k-\mu_{2}}{\sigma_{2}}\right)\right\}
$$

As $\mathrm{P} 1=\mathrm{g}\left(\mu_{1}\right)$ and $\mathrm{P} 2=h\left(\mu_{2}\right)$ with properties of $g^{\prime}\left(\mu_{1}\right)<$ 0 and $h^{\prime}\left(\mu_{2}\right)<0, \frac{\partial E(\pi)}{\partial \mu_{1}}=-\frac{\partial E(\pi)}{\partial P_{1}}$ and $\frac{\partial E(\pi)}{\partial \mu_{2}}=-\frac{\partial E(\pi)}{\partial P_{2}}$ that represents negative marginal profit of service fee. Whether an increase in service leads to economic gains or not depends on price elasticity. To simply our analysis, we assume that $\sigma_{1}$ is much smaller than $\mu_{1}$ and $\sigma_{2}$ is also much smaller than $\mu_{2}$. Thus, $\phi\left(\frac{\mu_{1}}{\sigma_{1}}\right)$ and $\phi\left(\frac{\mu_{2}}{\sigma_{2}}\right)$ equal to one and the second item in the bracket can be removed. Then, rearranging Eq. (A1.2) yields

$$
\begin{aligned}
& -g\left(\mu_{1}\right) /\left[\mu_{1} g^{\prime}\left(\mu_{1}\right)\right]= \\
& \frac{\left\{\frac{\sigma_{1}}{\sqrt{2} \pi}\left(e^{-\frac{\mu_{1}^{2}}{2 \sigma_{1}^{2}}}-e^{-\frac{(k-\mu)^{2}}{2 \sigma_{1}^{2}}}\right)+\mu_{1}\left[\phi\left(\frac{k-\mu_{1}}{\sigma_{1}}\right)-\phi\left(\frac{-\mu_{1}}{\sigma_{1}}\right)\right]+k\left(1-\phi\left(\frac{k-\mu_{1}}{\sigma_{1}}\right)\right\}\right.}{\mu_{1}\left\{\frac{-\mu_{1} \sigma_{1}}{\sqrt{2} \pi} e^{-\frac{\mu_{1}^{2}}{2 \sigma_{1}^{2}}}+\left[\phi\left(\frac{k-\mu_{1}}{\sigma_{1}}\right)-\phi\left(\frac{-\mu_{1}}{\sigma_{1}}\right)\right]+\mu_{1} \sigma_{1} f\left(\frac{-\mu_{1}}{\sigma_{1}}\right)+\frac{-\mu_{1}^{2}}{\sigma_{1}}\left(-\mu_{1}-k\right)\left(1-\phi\left(\frac{k-\mu_{1}}{\sigma_{1}}\right)\right\}\right.}
\end{aligned}
$$

Left-Hand-Side of Eq. (3.1) represents the demand elasticity in booming seasons, i.e $\varepsilon_{1}=\left(-d \ln \mu_{1}\right)$ / $\left(d \ln p_{1}\right)=-g\left(\mu_{1}\right) /\left[\mu_{1} g^{\prime}\left(\mu_{1}\right)\right]$. The result reveals that the service fee in booming seasons must be determined at the point where elasticity of market demand is equal to the ratio of average service rate to probable arrival. Similarly, the elasticity of market demand $\varepsilon_{2}=\left[-h\left(\mu_{2}\right) / h^{\prime}\left(\mu_{2}\right) \mu_{2}\right]$ in normal seasons should be equal to the ratio of average service rate to probable arrival similarly.

The sensitivity analysis confirms the results of $\frac{d k}{d c}<0$, $\frac{d \mu_{1}}{d c}>0, \frac{d \mu_{2}}{d c}<0, \frac{d k}{d q}>0, \frac{d \mu_{1}}{d q}<0$, and $\frac{d \mu_{2}}{d q}>0$. These results identify the properties that (1) an increase in operating costs leads to decreased service capacity, decreased arrival rate in booming seasons, and increased arrival rate in normal seasons and (2) longer booming seasons require increasing capacity, reducing arrival rate in booming seasons and increasing arrival rate in normal seasons. As the general assumption of market demand function owns the property of $\frac{d P_{1}}{d \mu_{1}}<0$ and $\frac{d P_{2}}{d \mu_{2}}<0$, thus we get the results of $\frac{d P_{1}}{d c}<0$, $\frac{d P_{2}}{d c}>0, \frac{d P_{1}}{d q}>0$, and $\frac{d P_{2}}{d q}<0$. The results show that the firm needs to use pricing strategies by reduce service fee in booming seasons and increase service fee in normal seasons when the operating costs increase. In contrast, the firm needs to increase service fee in booming seasons and reduce service fee in normal seasons when booming seasons become longer. The effects of seasonality on pricing strategies will be discussed in Section 5.

\section{B. Same Service Fee in Different Seasons}

If the management charges the same service fee in the two seasons, then, an implicit function to show the relationship between $\mu_{2}$ and $\mu_{1}$ is existent and can expressed as

$$
\mu_{2}=u\left(\mu_{1}\right)
$$

deriving from $\left.\mathrm{P} 1=g\left(\mu_{1}\right)=h\left(\mu_{2}\right)\right)=\mathrm{P} 2$, and Equation (3.2) becomes a constraint of Problem (P1). Therefore, the new problem is expressed as

$\underset{k, \mu_{1}, \mu_{2}}{\operatorname{Max}} \operatorname{qg}\left(\mu_{1}\right)\left[\int_{0}^{k} x f\left(x \mid \mu_{1}, \sigma_{1}^{2}\right) d x+\int_{k}^{\infty} k f\left(x \mid \mu_{1}, \sigma_{1}^{2}\right) d x\right]+$ $(1-\mathrm{q}) \mathrm{h}\left(\mu_{2}\right)\left[\int_{0}^{k} y f\left(y \mid \mu_{2}, \sigma_{2}^{2}\right) d y+\int_{k}^{\infty} k f\left(y \mid \mu_{2}, \sigma_{2}^{2}\right) d y\right]-\mathrm{ck}$ 


$$
\text { s.t. } \mu_{2}=u\left(\mu_{1}\right)
$$

This problem can be seen as a special case of Problem (P1). The optimal service fee $\mathrm{P}$ can be determined by the function of $\mathrm{P}=\mathrm{P} 1=\mathrm{g}\left(\mu_{1}\right)=\mathrm{h}\left(\mu_{2}\right)=\mathrm{P} 2$. We examine the effects of parameters on the optimality by taking total differentiation with parameters and get the results of $\frac{d k}{d c}<0, \frac{d \mu_{1}}{d c}>0, \frac{d k}{d q}>0$, and $\frac{d \mu_{1}}{d q}<0$. Thus, an increase in proportion $\mathrm{q}$ results in increased service capacity $\mathrm{k}$, but an increase in operating costs c will lead to decreased service capacity. As the general assumption of market demand function owns the property of $\frac{d P}{d \mu_{1}}<0$, thus $\frac{d P}{d q}>0$ and $\frac{d P}{d c}<0$ are derived. These results reveal that an increase in proportion $\mathrm{q}$ in booming seasons leads to an increase in service fee, but higher operating costs lead to a decrease in service fee when market demand is inelastic.

\section{A Competitive Market}

In a competitive market, service fee is fixed and given, determined by the equilibrium of market demand and supply. When the service fee cannot affect arrival rates in the two seasons, the firms seeks for optimized capacity by maximizing the expected profit of Problem (P1) and then the necessary condition is

$$
\begin{gathered}
q P_{1} \frac{1}{\phi\left(\mu_{1} / \sigma_{1}\right)}\left(1-\phi\left(\frac{k-\mu_{1}}{\sigma_{1}}\right)\right)+ \\
(1-q) P_{2} \frac{1}{\phi\left(\mu_{2} / \sigma_{2}\right)}\left(1-\phi\left(\frac{k-\mu_{2}}{\sigma_{2}}\right)\right)=c
\end{gathered}
$$

which is identical to Eq. (A1.1). The cumulative probability of $\frac{1}{\phi\left(\mu_{1} / \sigma_{1}\right)}\left(1-\phi\left(\frac{k-\mu_{1}}{\sigma_{1}}\right)\right)$ and $\frac{1}{\phi\left(\mu_{2} / \sigma_{2}\right)}\left(1-\phi\left(\frac{k-\mu_{2}}{\sigma_{2}}\right)\right)$ represents the probability that the service cannot satisfy the visitors demand in booming seasons and in normal seasons respectively. The optimal capacity of services facilities can be obtained through Eq. (3.3) indicating that operating costs of service facilities should be equal to the sum of expected opportunity costs.

The variation of parameters such as the proportion of booming seasons in a year $q$, operating costs of facilities $c$, and opportunity loss (service fee) $P$ may affect the optimum capacity for a service facility. Taking differentiation of services capacity $k$ with respect to $q, c, \mu_{1}, \sigma_{1}, \mu_{2}$, and $\sigma_{2}$ in Eq. (3.3) yields $\frac{d k}{d q}>0, \frac{d k}{d c}<0, \frac{d k}{d P}>0, \frac{d k}{d \mu_{1}}>0, \frac{d k}{d \sigma_{1}}>0$, $\frac{d k}{d \mu_{2}}>0$, and $\frac{d k}{d \sigma_{2}}>0$. These results, as we expect, indicate that (1) the longer the booming seasons $q$ requires more services facilities $k,(2)$ the increase in operating costs $c$ results in less capacity for a service facility $k$, (3) the increase in opportunity costs (service fee) $P$ leads to more services capacity $k$, (4) the increase in both arrival rates of $\mu_{1}$ and $\mu_{2}$ leads to the increase in services capacity $k$, and (5) the increase in both demand variances in the two seasons of $\sigma_{1}^{2}$ and $\sigma_{2}^{2}$ leads to the increase in services capacity $k$. Gu [22] employs a single period model to determine the optimal room capacity for hotels under a random demand. His model is quite similar to Problem (P1) in this paper. When the capacity of the facility is insufficient, customer cannot be accepted so that the firm will lose the revenue immediately, and thus the minus of revenue is seen as opportunity costs. Based on the sensitivity analysis of Eq. (3.3) we find that the cost ratio of opportunity costs due to insufficient capacity to operating costs plays the vital role in making determination of optimal capacity. The capacity will be decided at the point where the marginal operating costs equate to marginal opportunity costs as Eq. (3.3). In this paper, we employ truncated normal distributions of demand while $\mathrm{Gu}$ [22] uses a general distribution function of demand. We also investigate the effects of the uncertainty (the variance) on the capacity decisions and find that higher uncertainty (variance) will lead to more capacity of service facilities.

When price (service fee) is given and fixed, the aggregate demand for services is given and fixed. The service provided by the firm is identical to competitors in the market each of which behaves competitively. The firm is a price follower and only can attempt to minimize the total cost. This assumption seems to violate the practical world that the demand is variant and dynamical. Unless it cooperates with its competitors to form a cartel and implement the pricing strategy, the capacity is determined at the point where marginal operating costs equal to marginal opportunity costs. The capacity will be insufficient in booming seasons and low operating rate in normal seasons. The remedy is to differentiate the product (services of the facility) to increase monopoly power.

\section{CASE EXAMPLE AND MANAGEMENT IMPLICATIONS}

We focus on the solution of Problem (1) by employing a practical case. In this paper, we employ Nice-Prince Hotel (NPH) as a case example to demonstrate the effect of the operating costs of a service facility and the customer's arrival rates on the planned capacity and price setting. The plan site locates in Chiayi, a small city in South Taiwan and $50 \mathrm{~km}$ far from Alishan National Scenic Area (ANSA). Due to statutory regulation on land use, 5-star hotel is not allowed to construct within ANSA including Alishan National Forest Recreation Area (ANFRA), Danayigu and Rueli Taihe. In this case, all the passengers must stay in Chiayi overnight before departure for Alishan or after their visits. According to the information released from Tourism Bureau [23], passenger visits to ANFRA, Danayigu, and Rueli Taihe is 2,761,479, 121,061 and 43,852 respectively in 2014 (please see Table 1). About $60.9 \%$ of the total passengers spend one day only for touring [23]. This reflects that about $1,681,740$ passengers (equivalent to 2,926,392 times 57.4\%) are in need of room service in Chiayi in 2014. Based on the data, we assume that the total market demand for room service can reach to 1,334 rooms per day in Chiayi Region. 
Tourism Bureau [24] reports that the total sales revenue for a total of 58 international hotels in Taiwan is NT\$ 34.77 billion (including NT\$14.56 billion for room service and NT\$ 15.06 billion for food and drink service) for 6.59 million passengers and the average service fee (room charge) is NT\$ 3,294 in 2012. Before the construction of Hotel Prince, there are several smaller hotels and their offered service charges ranged from NT\$1,000 to 4,000 for single room per night in Chiayi.

According to the detailed planning of this project, passengers can enjoy about $30 \mathrm{sq}$ meter space in a single room, about $600 \mathrm{sq}$ meter of lobby, and other facilities such as restaurants, sauna, swimming pool etc in this hotel according to the original planning. As this project is designed to offer a high quality service for passengers that is differentiated from the locally existing hotel services, we assume Hotel Prince (Taiwan) is a monopoly in this area for the provision of such high quality service.

TABLE I: VISITORS TO ALISHAN NATIONAL SCENIC AREA

\begin{tabular}{|l|l|l|l|l|}
\hline & ANFRA & Danayigu & $\begin{array}{l}\text { Rueli } \\
\text { Taihe }\end{array}$ & total \\
\hline 2014 & $2,761,479$ & 121,061 & 43,852 & $2,926,392$ \\
\hline 2013 & $2,063,566$ & 57,775 & 36,434 & $2,157,775$ \\
\hline 2012 & $2,080,500$ & 49,451 & 32,276 & $2,162,227$ \\
\hline 2011 & $1,424,986$ & 42,573 & 18,227 & $1,485,786$ \\
\hline 2010 & 710,354 & 37,189 & 15,686 & 763,229 \\
\hline 2009 & $1,064,742$ & 78,752 & 51,811 & $1,195,305$ \\
\hline 2008 & 908,513 & 111,581 & 51,091 & $1,071,185$ \\
\hline 2007 & 842,251 & 105,455 & 70,434 & $1,018,140$ \\
\hline 2006 & 994,297 & 179,357 & 71,865 & $1,245,519$ \\
\hline 2005 & 724,201 & 178,627 & 66,842 & 969,670 \\
\hline 2004 & 695,266 & 187,476 & 56,780 & 939,522 \\
\hline 2003 & 699,768 & 213,785 & n.a. & 913,553 \\
\hline 2002 & 791,733 & 287,567 & n.a. & $1,079,300$ \\
\hline 2001 & 697,220 & n.a. & n.a. & 697,220 \\
\hline \multicolumn{5}{|c|}{ Source: Tourism Bureau (2015a) } \\
\hline
\end{tabular}

Forecasting future demand requires complicated techniques and elaborate procedures. In practical world, large firms in general depend on sophisticated software to analyze huge volume of data. We assume a linear demand function exists. An experimental survey was conducted to identify the demand function by asking (1) whether he is willing to pay for high quality hotel service of a hotel like Hotel Prince (Japan) in Chiayi, (2) how much he will pay for such a room service in booming seasons and normal seasons respectively. The respondents are composed of 100 undergraduate students in two classes separately and the conduct of the survey took about two days in January 2013 when the author presented in the class. The estimated results are expressed as $\mathrm{P}_{1}=7900-45 q_{1}$ for booming seasons, and $\mathrm{P}_{2}=5341-$

$32 q_{2}$ for normal seasons, where $q_{1}$ and $q_{2}$ represent the respondent's quantity demanded for room service in the two seasons respectively. The estimation method of the derived demand function and the survey procedure are very simple, but it does not lose the purpose that attempt to attempt to present the determination of optimal capacity and pricing through the case example.

We assume that the total market for room service can be differentiated into two sectors: international hotel and normal hotel. According to Tourism Bureau [23], International hotels provide 17,830 rooms, about $53.82 \%$ of total provisions of room service in Taiwan. Considering Chiayi is a small city that is not so developed in infrastructure and fashion life like Taipei or Taichung, we assume that NPH aims to acquire $25 \%$ of market share of hotel service in this region. As the total market demand is 1,334 rooms per day in Chiayi Region (please see the analysis in last paragraph in this section), the expected arrival rate for NPH will be 334 rooms per day (equivalent to 1,334 times 25\%). And thus, each respondent represents 3.34 passengers and the estimated demand for the room service provided by NPH is expressed as

$$
P_{1}=g\left(\mu_{1}\right)=7900-13.4 \mu_{1}
$$

for booming seasons, and

$$
P_{2}=g\left(\mu_{2}\right)=5341-9.6 \mu_{2}
$$

for normal seasons.

In general, people take a vacation on Saturday and Sunday in a week or Chinese festival days. Hotel management may receive more passengers in these vacation days (booming seasons). Tourism Bureau [23] releases the information that passengers touring on vacation days (booming seasons) accounts for $74.5 \%$, and thus we choose $q=0.745$.

Table II indicates that the operating costs (including the depreciation of the building, maintenance, and room cleaning) are estimated to be NT $\$ 1,800$ per day per room, i.e. $c=1,800$. The variance of market demand for the two seasons are assumed to be the same, i.e. $\sigma_{1}^{2}=\sigma_{2}^{2}=100^{2}$. This assumption may violate the practical experience, but it can simply the solving process of Problem (P1) and does not generate the negative impacts on the results.

TABLE II: THE ASSUMED PARAMETERS AND DEMAND FUNCTION

\begin{tabular}{|l|l|l|}
\hline Parameters/functions & notations & values \\
\hline Operating costs & $\mathrm{c}$ & $\mathrm{c}=1,800$ \\
\hline Proportion of booming seasons & $q$ & $q=0.745$ \\
\hline $\begin{array}{l}\text { Demand function in booming } \\
\text { seasons }\end{array}$ & $P_{l}=g\left(\mu_{1}\right)$ & $\begin{array}{l}P_{l}=7900 \\
-13.4 \mu_{1}\end{array}$ \\
\hline $\begin{array}{l}\text { Demand function in normal } \\
\text { seasons }\end{array}$ & $P_{2}=g\left(\mu_{2}\right)$ & $\begin{array}{l}P_{2}= \\
5341-9.6 \mu_{2}\end{array}$ \\
\hline $\begin{array}{l}\text { Variance of arrival rate in } \\
\text { booming seasons }\end{array}$ & $\sigma_{1}^{2}$ & $\sigma_{1}^{2}=100^{2}$ \\
\hline $\begin{array}{l}\text { Variance of arrival rate in normal } \\
\text { seasons }\end{array}$ & $\sigma_{2}^{2}$ & $\sigma_{2}^{2}=100^{2}$ \\
\hline
\end{tabular}

Based on the assumed data in Table I, the solution is solved by the package of Maple $\mathrm{V}$ and the results of $\mu_{1}=$ 241, $\mu_{2}=150$ and $k=223$ are obtained. The results indicate that the size of 223 rooms for hotel service may be the optimal capacity in Nice Prince Hotel, and service fee of NT\$ 4,670 and NT\$ 3900 in booming seasons $P_{l}$ and normal seasons $P_{2}$ respectively may bring about maximized expected profit. The optimal capacity for hotel services falls in between the mean arrival rates of the two seasons that are implicitly determined by the service fee of room service in the hotel.

As higher demands fall in booming season, the price will be marked up in booming seasons. The service provider may 
enjoy higher relative benefits in booming seasons with higher price while customers may be compensated from low costs of traveling (lower price of ticket fees or hotel charges) in normal seasons. As $P_{1}=g\left(\mu_{1}\right)$ and $P_{2}=h\left(\mu_{2}\right)$, the price markup $\Delta P$ in booming seasons is expressed as $\Delta P=P_{1}$ - $P_{2}=g\left(\mu_{1}\right)-h\left(\mu_{2}\right)$. Through sensitivity analysis, we find that $\frac{d \Delta P}{d c}<0$ and $\frac{d \Delta P}{d q}>0$ because of $\frac{d P_{1}}{d c}<0, \frac{d P_{2}}{d c}>0$, $\frac{d P_{1}}{d q}>0$, and $\frac{d P_{2}}{d q}<0$ (please see the analysis results in Section 3.1). The price markup in booming seasons will be higher if the proportion of booming seasons increase, but lower if the operating cost increases. The price markup (the price difference between the two seasons) depends on the demand elasticity in the two seasons. For example, it is difficult for customers to change working schedule and cannot move vacation schedule from booming seasons (summer vacation) to normal seasons due to inflexible job requirements.

Seasonality is an important factor to affect the determination of capacity and perceived as a major problem for management [25]. The main causes may stem from natural factors such as regular weather fluctuations in a destination, or from institutional factors such as traditional festivals, summer vacations, Chinese New Year, or from social factors such as sporting calendars, etc. All these factors will affect human activities and result in congestion for some particular services dues to intensive demand in a short time. The effect of seasonality on pricing provides some highlights for testing models of price markup in booming seasons which market demand fluctuates over the seasonal cycle.

In this paper, we employ three parameters to describe the status of seasonality by incorporating (1) the proportion of booming seasons in a year, (2) arrival rates and (3) demand variances. To resolve the dynamic problems, this paper treats the seasonal demands by dividing up the period of service into two seasons and applies static analysis to each interval separately [26]-[28]. In fact, the intervals (seasons) can be extended to be more than two, i.e. $\sum_{i} q_{i}=1$, where $q_{i}$ is the

proportion of $i$ th season in a year. The demand function for services in each season is assumed to be randomly distributed, but given and fixed, i.e. $P_{1}=g\left(\mu_{1}\right)$ and $P_{2}=h\left(\mu_{2}\right)$, and the actual value of $q$ is also fixed and given. The proportion and the demand function can be determined through data analysis of statistical methods over the trend-cycle of the series [28]-[34]. Many researchers employ various techniques to estimate the dynamic relationship between demanded quantity, price and other determinants for a variety of application such as demands for electricity, recreation, hospitality etc. Fernandez-Morales [32] analyzes seasonal concentration in tourism demand series and find a significant existence of the proportion rate between seasons. Bar-On [36] also finds the regularity of seasonality in each year that the effects occurring with the same timing and magnitude.

In fact, the determination of capacity involves the current investment, future return of capital, the employment recruits, as well as adverse effects on the environment, caused either by the overuse of the facilities or by the sudden and intensive visits on the environment during the booming season. The results of this paper find that the higher uncertainty requires more investment on the capacity of facilities and may reduce the net profit of the investments. Bean et al. [37] find that high demand variance will cause a firm management to delay its expansion project and reduce its expansion sizes. In this paper, we are not interested in future expansion but focus on the initial capacity choice of service facilities through pricing strategies. The results of the model show that the management can increase the price gap between the two seasons to reduce seasonality. In normal seasons, service fee is reduced to attract more customers. The results are consistent with the finding of other researchers who focus on the traffic problem for peak and off-peak periods to mitigate congestions [38]-[39].

The variations in demand across seasons that generally reflect the customer's time cost will result in some periods of under-utilized capacity and slack in the labor force and some periods of insufficient provision. The firm will face the limited skilled labors in booming seasons and excessive slacks in normal seasons. Thus, dynamic pricing can be significantly more efficient and also more responsive to demand changes across seasons. The provision through pricing strategies for multiple differentiated levels of service with multiple priority classes operating in an efficient economic market is also an effective tool to reduce the demand variation across seasons. To overcome the seasonal uncertainty, some strategies have been adopted. For example, the variation in the product mix by providing adequate facilities for international conferences, or food services attached to the hotel and the use of price differentials [40], or the non-refundable discounted room rates for customers who were willing to purchase in advance [41] may be effective strategies to offset the season demand uncertainty in addition to profit-oriented pricing.

All the conclusions are derived based on the assumption of a profit-seeking firm. This means that other market objectives may influence pricing decision. For example, the objectives of market-share leadership, brand equity growth, product-quality leadership, cross-selling and upselling generally direct the management to conduct pricing [40].

The above discussions are based on the assumption that the firm is a monopoly that can dominate market demands. It can adjust the customer visit frequency by adjusting price between the two seasons. However, this paper implies that the price adjustment between the two seasons does not affect the proportion $q$. In other words, the arrival rates $x$ and $y$ are independently distributive.

\section{Conclusions}

It is generally recognized that the business environment is apt to change in a modern business in which the industry structure and market environments is full of uncertainty and challenges. The main contributions of the present paper are (1) to examine the effects of dynamical seasonal demand into static analysis by dividing the seasons into booming seasons and normal seasons, and (2) to investigate the effects of 
demand level and uncertainty on the capacity choice of facilities. The presented two models can be applied to firms that face different situations or locate in different regions. The results derived in this paper can help the firm management to make choice decisions on the capacity of facilities and to formulate their resource allocation strategy efficiently by incorporating the environmental parameters such as operating costs, service fees, arrival rates and demand variances into the models.

However, the pricing on service fees in these models neglects the negative externalities of the service that is occurred with the finite carrying capacity in a region. In fact, the environmental deterioration caused by human activities or over-use on the environment is gradually received due attention by many authors [42]-[47]. Stringent regulation on land use to avoid over-development is needed and focuses on the avoidance of fringe of the woods or forests in the environment. New development project (e.g. the installation of a new facility) must meet the regulation that harmoniously into the existing natural environment to assure that the objectives of sustainability can be achieved. The concept of carrying capacity and the negative effects of infrastructure service on environment may be considered into the model for the future study.

\section{REFERENCES}

[1] Bureau of Statistics, Taiwan. (2015). Table 25. Employed person by industry. [Online]. Available: http://www.eng.dgbasey.gov.tw

[2] Bureau of Statistics, Taiwan. (2015). Gross domestic product by kind of industry. [Online]. Available: http://www.eng.dgbasey.gov.tw

[3] M. Xu and X. Zhuan, "Optimal planning for wind power capacity in an electric power system," Renewable Energy, vol. 53, pp. 280-286, 2013.

[4] D. J. Shemwell and J. J. Cronin, "Service marketing strategies for coping with demand/supply imbalance," Journal of Service Marketing, vol. 8, pp. 14-23, 1994.

[5] M. Pullman and S. Rodgers, "Capacity management for hospitality and tourism: A review of current approaches," International Journal of Hospitality Management, vol. 29, pp. 177-187, 2010.

[6] C. Bozarth and R. Handfield, Introduction to Operations and Supply Chain Management, Pearson-Prentice Hall, Upper Saddle River, NJ, 2006.

[7] M. I. Malik and M. S. Bhat, "Sustainability of tourism development in Kashmir - Is paradise lost?" Tourism Management Perspectives, vol 16, pp. 11-21, 2015.

[8] H. Corsten and S. Stuhlmann, "Capacity management in service organizations," Technovation, vol. 18, no. 3, pp. 163-178, 1998.

[9] Y. Gerchak, E. Hassini, and S. Ray, "Capacity selection under uncertainty with ratio objectives," European Journal of Operational Research, vol. 143, pp. 138-147, 2002.

[10] M. C. Gelhausen, "Modelling the effects of capacity constraints on air travellers' airport choice," Journal of Air Transport Management, vol. 17, pp. 116-119, 2011.

[11] J. Hwang, L. Gao, and W. Jang, "Joint demand and capacity management in a restaurant system," European Journal of Operational Research, vol. 207, pp. 465-472, 2010.

[12] R. Thomas and E. Wood, "The absorptive capacity of tourism organisations," Annals of Tourism Research, vol. 54, pp. 84-99, 2015.

[13] P. R. Harper, A. K. Shahani, J. E. Gallagher, and C. Bowie, "Planning health services with explicit geographical considerations: a stochastic location-allocation approach," Omega, vol. 33, pp. 141-152, 2005.

[14] A. Glazer and L. S. Rothenberg, "Increased capacity may exacerbate rationing problems: with applications to medical care," Journal of Health Economics, vol. 18, no. 5, pp. 671-680, 1999.

[15] J. I. Daniel, "Distributional consequences of airport congestion pricing," Journal of Urban Economics, vol. 50, no. 2, 230-258, 2001.

[16] J. Calfee and C. Winston, "The value of automobile travel time: Implications for congestion policy," Journal of Public Economics, vol. 69, pp. 102-183, 1998.
[17] G. M. Thompson, "Restaurant's seating capacity, use dedicated or combinable tables?" Cornell Hotel and Restaurant Administration Quarterly, pp. 48-57, 2002.

[18] L. F. F. Miguel and L. F. F. Miguel, "Shape and size optimization of truss structures considering dynamic constraints through modern metaheuristic algorithms," Expert Systems with Applications, vol. 39, pp. 9458-9467, 2012.

[19] B. Desart, D. Gillingwater, and M. Janic, "Capacity dynamics and the formulation of the airport capacity/stability paradox: A European perspective," Journal of Air Transport Management, vol. 16, pp. 81-85, 2010.

[20] S. E. Kimes, R. B. Chase, S. Choi, E. N. Ngonzi, and P. Y. Lee, "Restaurant revenue management," Cornell Hotel and Restaurant Administration Quarterly, vol. 40, no. 3, pp. 40-45, 1998.

[21] J. Grossman, A. Thomas, and M. L. Brandeau, "Optimal pricing for service facilities with self-optimizing Customers," European Journal of Operational Research, vol. 141, pp. 39-57, 2002.

[22] Z. Gu, "Analysis of Las Vegas strip casino hotel capacity: An inventory model for optimization," Tourism Management, vol. 24, pp. 309-314, 2003.

[23] Tourism Bureau, MOTC, Republic of China. (2015). An analysis on the operation of international hotel. [Online]. Available: http://admin.taiwan.net.tw/indexc.asp.

[24] Tourism Bureau, MOTC, Republic of China. (2015). Visitors to principal scenic spots in Taiwan. [Online]. Available: http://admin.taiwan.net.tw/indexc.asp

[25] T. Baum, "Seasonality in tourism: Understanding the challenges," Tourism Economics, vol. 5, pp. 5-8, 1999.

[26] R. Arnott, A. Palma, and R. Lindsey, "A structural model of peak-period congestion: a traffic bottleneck with elastic demand," American Economic Review, vol. 83, pp. 161-179, 1993.

[27] R. Butler and B. Mao, "Seasonality in Tourism: Problems and measurement," Quality Management in Urban Tourism, pp. 9-23. Chichester: Wiley, 1997.

[28] C. Lim and M. McAleer, "Monthly seasonal variations: Asian tourism to Australia," Annals of Tourism Research, vol. 28, pp. 68-82, 2001.

[29] M. Beenstock, E. Goldin, and D. Nabot, "The demand for electricity in Israel," Energy Economics, vol. 21, pp. 168-183, 1999.

[30] R. F. Engle, C. W. J. Granger, S. Hylleberg, and H. S. Lee, "Seasonal cointegration: The Japanese consumption function," Journal of Econometrics, vol. 47, pp. 275-298, 1993.

[31] F. L. Joutz, G. S. Maddala, and R. P. Trost, "An integrated bayesian vector autoregression and error correction model for forecasting electricity consumption and prices," Journal of. Forecast, vol. 14, pp. 287-310, 1995.

[32] A. Fernandez-Morales, "Decomposing seasonal concentration," Annals of Tourism Research, vol. 30, no. 4, pp. 942-956, 2003.

[33] T. C. Haab, "Temporal correlation in recreation demand models with limited data," Journal of Environmental Economics and Management, vol. 45, pp. 195-212, 2003.

[34] C. Goh and R. Law, "Modeling and forecasting tourism demand for arrivals with stochastic nonstationary seasonality and intervention," Tourism Management, vol. 23, pp. 499-510, 2002.

[35] E. Kennedy, "Seasonality in Irish Tourism: 1973-1995," Tourism Economics, vol. 5, pp. 25-48, 1999.

[36] R.Bar-On, "The measurement of seasonality and its economic impacts," Tourism Economics, vol. 5, pp. 437-458, 1999.

[37] J. C. Bean, J. H. Higle, and R. L. Smith, "Capacity expansion under stochastic demands," Operations Research, vol. 40, S2, S210-S216, 1992.

[38] J. Allcock, "Seasonality," Tourism Marketing and Management Handbook, pp. 86-92. New York: Prentice Hall, 1994.

[39] R. Butler, "Seasonality in tourism: Issues and problems," Tourism: The State of the Art, pp. 332-340. Chichester: Wiley, 1994.

[40] P. Kotler, J. T. Bowen, and J. C. Makens, "Marketing for hospitality and tourism," New Jersey: Pearson Education Ltd., 2006

[41] K. S. Lee and I. C. L. Ng, "Advanced sale of service capacities: A theoretical analysis of the impact of price sensitivity on pricing and capacity allocations," Journal of Business Research, vol. 54, pp. 219-225, 2001.

[42] G. C. Daily and P. R. Ehrlich, "Population, sustainability, and Earth's carrying capacity," BioScience, vol. 42, no. 10, pp. 761-771, 1992.

[43] G. Hardin, "Cultural carrying capacity: A biological approach to human problems," BioScience, vol. 36, no. 9, pp. 599-604, 1986.

[44] D. G. Pearce, "Tourism and environmental research: A review," International Journal of Environmental Studies, vol. 25, no. 4, pp. 247-255, 1985. 
[45] A. Haulot, "The environment and the social value of tourism," International Journal of Environmental Studies, vol. 25, no. 4, pp. 219-223, 1985

[46] D. Davis and C. Tisdell, "Recreational scuba-diving and carrying capacity in marine protected areas," Ocean \& Coastal Management, vol. 26, no. 1, pp. 19-40, 1995.

[47] I. Seidl and C. A. Tisdell, "Carrying capacity reconsidered: From Malthus' population theory to cultural carrying capacity," Ecological Economics, vol. 31, pp. 395-408, 1999.

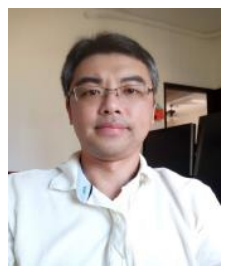

Yi-Tui Chen was born in July 22nd, 1980 in Taipei, Taiwan. $\mathrm{He}$ is with the Department of Business Administration, National Central University, Taoyuan, Taiwan. He received the $\mathrm{Ph}$. D degree of management in 2009 and the major field is environmental management. He worked an assistant professor and then promoted to associate professor in the Department of Health Care Management at National Taipei
University of Nursing and Health Sciences in 2010 and 2014, respectively.

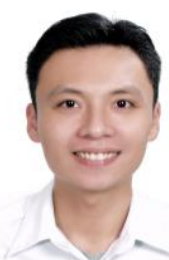

Fu-Chiang Yang was born in September 4, 1982 in Taipei, Taiwan. He is with the Department of Business Administration, National Central University, Taoyuan, Taiwan. He received his Ph.D degree of management in 2011 and the major field is environmental management. He worked an assistant professor and then promoted to associate professor in the Department of Business Administration at Delin University of Technology in 2012 and 2017, respectively. 